\title{
Génesis, desarrollo y cristalización de la teoría y política económica agrarias de Campomanes
}

\author{
Manuel Bustos Rodriguez *
}

\section{UNA VIEJA PREOCUPACIÓN}

La preocupación de Pedro Rodriguez Campomanes por los temas agrarios es bastante temprana, como lo demuestra su carta a Francisco Pérez de Soelmonte, fechada en 1752, es decir, cuando nuestro personaje apenas cuenta 29 años ${ }^{\dagger}$. En ella, escrita aún con un lenguaje poco depurado, expone sus conceptos básicos acerca de la Naturaleza y la nueva ciencia agrícola, al tiempo que nos demuestra su conocimiento de la obra de ese gran teórico-práctico de la agricultura del siglo xVIII Ilamado Jetro Thull. Por este tiempo, su contacto con los clásicos del pensamiento agrario (Columela, Abu Zacaria Yahia) es un hecho, y en la carta referida aparecen ya alusiones a los escritos de ambos autores. Del último precisamente, Campomanes había traducido un año antes dos importantes capítulos de su Libro de Agricultura, junto con el arabista Casiri, luego insertos en una traducción de la obra de Thull sobre el cultivo de la tierra, que el propio prócer ilustrado contribuye a divulgar ${ }^{2}$.

* Universidad de Cádiz.

- Fundación Universitaria Española: Archivo Campomanes (en adelante A.C.), 16/23 bis. La carta está publicada en Pedro Rodriguez Campomanes, Epistolario, Miguel Avilés (dir.), Madrid 1983, vol. I, 1747-1777. En adelante lo citaremos como Epist.

${ }^{2}$ Los capitulos, traducidos en 1751, van colocados como Apéndice en el Tratado del cultivo de las tierras, según los principios de Mons. Tull, compuesto en francés por Mons. Duhamel de Monceau y en español por Miguel Joseph de Aoiz. En cuanto al Libro de Agricultura, existe publicación en Madrid, Imprenta Real, 1802, en dos vols., a cargo de José Antonio Banqueri (presbitero). 
Por otra parte, la inquietud campomanista por los temas del campo se inserta en un tiempo de excepcional importancia para el agro europeo, justo cuando el interés por el mismo se acrecienta en todo el continente, la llamada revolución agrícola inicia su despegue más decidido y los precios de los productos agrarios mantienen un progresivo ascenso, capaz de desencadenar, entre otros hechos, una verdadera presión sobre la tierra en general y su tenencia en particular ${ }^{3}$. Con los ejemplos holandés y - sobre todo- inglés, que no le abandonan ya en toda su trayectoria de escritor de temas económicos, Campomanes se introduce de lleno en la vigorosa corriente de renovación agricola que recorre Europa. En este sentido, aunque con resultados distintos, su nombre debería situarse con respecto a España, al lado de los de sus coetáneos de otras naciones: el referido Thull, Young, Duhamel de Monceau, Wallerius, Timci o el propio Galiani, por sólo citar algunos de los más conocidos. Así pues, nuestro país no ha carecido en este campo de una figura al menos de excepcional importancia - Campomanes-, llamada a plantear la sin duda más completa y profunda política económica agraria del siglo xVIII en España. Este empirismo agrario ${ }^{4}$ estará llamado, mejor aún que las propias doctrinas fisiócratas, a sentar las bases de la futura renovación y modernización del espacio agrario. Campomanes conoce la obra de estos autores, a los que cita con frecuencia, compartiendo con ellos unas mismas inquietudes y deseos; pero tampoco le serán ajenos los textos de nuestros arbitristas (Martinez de Mata, Álvarez Osorio, Fernández Navarrete, Caxa Leruela o Cellorigo), con quienes se encuentra muy familiarizado y cuya obra contribuye decisivamente a divulgar ${ }^{5}$

En la fecha referida de 1752 hallamos, pues, un primer testimonio de excepcional importancia a la hora de fijar la posición agrícola inicial de Campomanes. Nuestro ilustrado, que no ha conocido todavía la gloria del triunfo político, empieza a destacarse como hombre de conocimientos vastísimos y reformador nato. En efecto, llegado a Madrid diez años antes, el asturiano (había nacido en Santa Eulalia de Sorriba, Concejo de Tineo, en 1723) es ya un personaje conocido en los círculos intelectuales de la Corte, donde ejerce como abogado eminente, y empieza a atraer

${ }^{3}$ Cfr. A. Soboul, G. Lemarchand y Michèle Fogel: Le siècle des Lumières, Paris 1977, P.U.F., vol. I, pp. 239-40. Para España cfr. Gonzalo AnES: Las crisis agrarias en la España moderna, Madrid, Taurus, 1970.

${ }^{4}$ Paul Mantoux: La révolution industrielle au XVIII siècle, Paris, 1959, p. 152.

${ }^{5}$ Campomanes reunirá en la Biblioteca de la Academia de la Historia los Discursos y el epitome de Francisco Martinez de Mata, divulgándolos en el Apéndice a la Educación Popular. Otro tanto hará con el Discurso de Álvarez Osorio. 
sobre sí la atención de los ministros reformistas como Ensenada o Wall ${ }^{6}$. $\mathrm{Su}$ interés por la res publica viene entonces a manifestarse en algunas propuestas concretas que aparecen formuladas en su carta a Soelmonte.

\section{LOS PRIMEROS PASOS}

A estas alturas, Campomanes plantea la necesidad de un cambio en la naturaleza, método y objeto del conocimiento como paso previo a la renovación agraria que España necesita. El armazón teórico viene así a colocarse como sostén imprescindible de las propuestas de tipo práctico que abordará en segundo lugar. Dios, autor de la Naturaleza, ha creado ésta dándole un orden, cuyas leyes reguladoras deben ser tarea fundamental del conocimiento humano. Mediante la observación y la experiencia bien "dirigida y puntualizada" -expresa el asturiano- se puede llegar a la captación de aquéllas, gracias a la repetición de los fenómenos, que una vez aprehendidos, suministran el saber necesario a la correcta actuación del hombre en su favor ${ }^{\text {? }}$.

A continuación, Campomanes trasladará estos principios al ámbito agrícola para mostrar de qué manera pueden éstos actuar sobre él. Así, la tierra posee unas cualidades o propiedades que el simple arrendatario y el propietario deben conocer a fondo a fin de lograr la utilidad apetecida, que el prócer ilustrado resume en el hecho de obtener los mejores rendimientos mediante el mayor ahorro posible de tiempo dedicado al trabajo y en la facilidad para su ejercicio. Tales cualidades podrían ser ordenadas según las categorías siguientes: color, sabor, peso y grado de cohesión. A través de ellas, mediante el uso de la experiencia, el campesino podrá conocer la relación de todas y cada una de ellas con la fertilidad de la tierra $y$, en consecuencia, las propias exigencias del cultivo. En esta carta, convertida en auténtico tratado de agricultura, Campomanes explicita uno a uno los pasos que será preciso dar: toma de muestras, según tres niveles diferentes (pueblo, distrito y haza); análisis, en profundidad y superficie, de la parte correspondiente a minerales (me-

${ }^{6}$ Cfr. Laura Rodriguez: Reforma e Ilustración en la España del siglo XVIII: Pedro Rodriguez Campomanes, Madrid, F.U.E., 1975, pp. 84-85.

7 Carta de Campomanes a Frco. Pérez de Soelmonte, Madrid, 20-VIII-1752. 
tales escribe él) distinguiéndola de la tierra propiamente dicha; comparación de las diferentes tierras y de los frutos por éstas producidos, y, por último, establecimiento de relaciones (peso-color, sabor-peso, etc.). A partir de ahí se podria llegar finalmente al conocimiento de la causa o las causas de los fenómenos y a la formulación de unas reglas, que Campomanes, en favor de su correcta comprensión, desea sean pocas. El mismo lo resume con claridad en esta máxima: “Apurar esta materia (del aprovechamiento de los suelos) a fuerza de observarla (la tierra), sin dar por asentada cosa que la repetida experiencia no hubiese certificado" ${ }^{8}$.

Este empirismo agrario, dirigido tal vez a los patriotas cultos e instruidos - el asturiano no lo expresa-, habrá de dar origen a un conocimiento verdaderamente útil para uso de los labradores en beneficio propio. Campomanes lo precisa mejor: este conocimiento (inserto en su optimista visión del tiempo histórico y su fe en el progreso) se acrecienta de cara al futuro; de otra parte, al tener un carácter universal, puede servirse de experiencias ajenas (no necesita, pues, descubrirlo por sí mismo todo), abriéndose por lo tanto hacia otros a fin de enriquecerse mutuamente.

Las experiencias así obtenidas podrán tener cabida en un espacio limitado. Por eso propone Campomanes la erección en cada pueblo de un jardín botánico, donde se trabajaría en común, bajo la dirección de profesores de Botánica y de Medicina-Cirugia (éstos últimos por el valor curativo de ciertas plantas), que al tiempo de enseñar, aprovechan para si mismos las experiencias en él adquiridas. En resumidas cuentas, ese pequeño seminario - como lo califica el asturiano-, «instruiría más en los libros naturales de las plantas, que todas nuestras Universidades" ${ }^{9}$.

Pero, junto a este empirismo naturista, Campomanes se atreve a plantear a Soelmonte algunos de los temas en los que reincidirá en posteriores escritos suyos. Si la revolución del conocimiento ha de redundar en favor de una utilidad y rentabilidad del suelo mayores, diversos aspectos técnicos, sociales y hasta psicológicos contribuyen también al mismo fin. Así, el enraizamiento del campesino o la seguridad de poder continuar en su tierra durante largo tiempo. Sin embargo, Campomanes sabe que ello no será posible si no se aborda de forma paralela una política de rentas que haga posible esta situación, en un país como España,

\footnotetext{
8 Ibidem.

9 Ibidem.
} 
donde la mayoría del campesinado no posee la tierra en propiedad. Campomanes aboga por su congelación 0 , incluso, reducción, a fin de que el arrendatario se anime a la inversión e introduzca los cambios necesarios con vistas a un aumento de los rendimientos. Mejor aún, sería conveniente otorgar al campesino el acceso a la propiedad por medio de la redención de los censos ${ }^{10}$.

Y al lado de las rentas, el desarrollo agrario del país exige para Campomanes la mecanización del campo, la introducción de nuevos cultivos y el mejor aprovechamiento de sus recursos. Con relación a lo primero, el asturiano hace a su interlocutor una extensa relación sobre el tema, basada en la obra de Thull. Las máquinas deberán reunir, en su opinión, tres condiciones fundamentales: seguridad, rapidez, más facilidad de uso y fabricación (esto último, apoyado en su deseo, perceptible ya en la epístola, de hacer al campesino constructor de sus propios útiles de trabajo, fruto del conocimiento aplicado a la técnica al que tanta importancia concedia). Señala en especial el uso de las sembraderas, y se refiere también a la necesidad de extender, «razonadamente», el empleo de las máquinas ".

Estos ingenios no impiden, sin embargo, el recurso a las bestias, sobre las que Campomanes tiene algo que decir. Sugiere la conveniencia de cambiar las mulas por bueyes, al considerar que éstos realizan un trabajo más seguro y profundo -en la línea propuesta por Thull-, beneficiando la tierra con sus pisadas y estiércol. Además, cosa nada desdeñable, su mayor coste quedaría compensado por las necesidades de herraje y otros cuidados exigidos por los caballos, así como por las mayores posibilidades alimenticias de su carne.

La introducción de nuevos cultivos, constante de la reforma agraria campomanista, tiene también cabida en este año de 1752. En efecto, se refiere ahora a la adaptación de nuevas semillas, previo el estudio de la tierra llamada a recibirlas, con especial atención a los prados artificiales que han de permitir una mejor alimentación del ganado. Importa, además, la transformación de suelos incultos o deficientemente cultivados en pastos, frutales o huertas. Pero la aplicación de la misma exige la reutilización del suelo, afectando así a los espacios tradicionalmente destinados a la alimentación de los ganados transhumantes, tales las dehesas. Cam-

\footnotetext{
${ }^{10}$ Ibidem.

11 Ibidem.
} 
pomanes, por el momento, no hace alusión a ellos, y mucho menos a la rancia institución que les da cobijo - la Mesta-, llamada a ser con posterioridad la "bestia negra" de la renovación agrícola. Le basta ahora con recordar a su admirado Soelmonte la conveniencia de romper las dehesas a fin de aumentar las cosechas y los pastos.

Las posibilidades de la Naturaleza son enormes. Paradójicamente, Campomanes señala su deficiente uso; de ahí la necesidad de aplicar los conocimientos siempre crecientes al aprovechamiento de las aguas de los ríos (uso de diques) y subterráneas (norias). Pero a la postre, éstas y las medidas referidas anteriormente exigen una capitalización del agro hispano, en particular del castellano. En otras palabras, para acometer inversiones en maquinaria, nuevos cultivos o aprovechamiento de los recursos naturales son precisas fuentes de financiación. Campomanes propugna el fomento de las acciones (sic) y compañias como vía hacia la realización de inversiones de importancia en el campo ${ }^{12}$.

\section{LA DÉCADA DE LOS SESENTA}

La de los años sesenta se puede considerar como una nueva etapa en el despliegue de la teoría y la práctica agrarias campomanistas, aunque estrechamente vinculada a la anterior. Campomanes, que ha obtenido en 1754 permiso oficial para leer libros prohibidos, continúa su línea ascendente en el aparato del Estado, siendo nombrado, casi un año después, asesor de Correos, gracias al apoyo y protección que le ofrece Bernardo Ward. En 1756 solicitaba del rey los honores y antigüedad de Fiscal de la Sala de Alcaldes de Casa y Corte ${ }^{13}$, uno de los tres cuerpos en que, tras la reforma de 1715, se dividía el Supremo Consejo de Castilla. La contestación del monarca llegará unos años más tarde, haciéndole, sucesivamente, Ministro Togado del Consejo de Hacienda ${ }^{14}$ y Fiscal del Consejo (1762). Con estos títulos en mano, el asturiano entraba en la institución más dinámica del Estado borbónico, lugar desde donde se libraría la batalla fundamental del reformismo. Se abría así un

12 Ibidem.

13 A.C., 11/9.

14 A.C., $11 / 11$. 
periodo de fecundísima actividad, donde los grandes temas del XVIII español (desamortización eclesiástica, libre comercio, reforma agraria, reducción del poder inquisitorial, etc.) entrarán en liza. Por esta misma época de los sesenta (1767) accede Campomanes también al cargo de Fiscal del Tribunal de la Cámara de Castilla, equiparable a un Consejo privado del rey, formado a partir del de Castilla ${ }^{15}$.

La participación en los órganos de Gobierno, a los que ha llegado con una acrisolada fama de hombre sabio e infatigable trabajador, le permite a la par el desarrollo de sus ideas sobre el campo y la posibilidad de impulsarlas desde el poder. Por eso, nuestro prócer se compromete en mayor medida con la obra legislativa de Carlos III, adoptando un discurso mucho más político, que busca la aplicación de soluciones prácticas concretas sin perder de vista el conjunto, en la línea iniciada en la etapa anterior. De los años sesenta son varios documentos y obras de gran importancia cuyo análisis deberemos ahora acometer.

Campomanes, aunque disminuida en su intensidad, no abandona en este período su interés por la instrucción agrícola. Como antes, inserta ahora esta necesidad en el esquema general de las Luces. El pueblo, viene a decir a su amigo, el economista Craywinkel, en una importantísima carta de 1760 , carece de las luces necesarias y no profundiza en las cosas; de ahí que la fuerza de la costumbre y las falsas ideas vengan arrástrándole hacia soluciones inadecuadas que, en el ámbito de la agricultura, producen persistentemente daños. El Gobierno ilustrado -el asturiano se expresa ya como hombre público-, por el contrario, debe ir a las causas que originan los problemas y actuar a su luz ${ }^{16}$. $Y$ tal ha de ser su postura con respecto al campo: atajar las causas de su decadencia facilitando los medios de salir de ella. Pero, lejos de ser la del Estado una actitud intervencionista y hasta coercitiva, importa se ciña a despejar el camino y limpiarlo de obstáculos a fin de que aflore la libre iniciativa. Tal posición, claramente liberal, se opone a esa otra imagen de un Campomanes altamente estatista, que nos han suministrado algunos estudios sobre el pensamiento de la ilustración española ${ }^{17}$. En efecto, el asturiano, que retoma en esta nueva etapa con más fuerza su vieja aspira-

${ }^{15}$ Cfr. L. Rodriguez: op. cit., pp. 67-73.

${ }^{16}$ A.C., Carta de Campomanes a Frco. Craywinkel. Madrid, 4-IV-1760, 14/1, y Epist., pp. 68-78. En ella Campomanes expresa a su amigo lo siguiente: El orden politico se ha de templar por el curso de las cosas y no precisamente por la naturaleza de ellas (p. 74).

17 Asi, por ejemplo, recientemente, Javier VARELA: Jovellanos, Madrid, Alianza Universidad, 1988, pp. 118 y sigs. 
ción a ofrecer alternativas concretas a los problemas del agro, al objeto de que las haga suyas el Estado, se referirá ahora a varias medidas liberalizadoras de gran importancia.

Comprendiendo que la economía es un todo en donde cada una de las partes se interrelaciona, Campomanes aborda uno de los temas más trascendentales y polémicos de los años sesenta: el libre comercio de granos ${ }^{18}$. Su marco, sin embargo, desbordará lo puramente cerealístico para convertirse en acto de afirmación global sobre los beneficios del libre comercio en general. Pero lo que aquí nos interesa es poner de manifiesto, además del liberalismo campomanista, la íntima conexión que el asturiano establece entre circulación de productos agrarios (los granos en este caso), mejora de las condiciones del campo y nivel económico de campesinos y propietarios. Como el tema ha sido en parte estudiado ${ }^{19}$, nos bastará aquí con mostrar aquellos aspectos que más importan al desarrollo del pensamiento agrario campomanista.

El objetivo del asturiano será el de obtener el mejor precio posible de los granos, en la consideración de que, cuanto más elevado sea éste, tanto más beneficio obtiene el labrador con sus ventas, y el jornalero con el cobro de su salario aumentado. No sólo ellos, también el clero (a través de los diezmos) y la nobleza terrateniente por el aumento de sus rentas. No hay clase o grupo que no aproveche el flujo benefactor originado por el libre comercio. Los propios artesanos beneficiarán sus bolsillos por el incremento de la demanda general de manufacturas; hasta el consumidor podrá comprar a los mejores precios posibles, ya que por su acción, la libre concurrencia los lleva a su justa medida ${ }^{20}$. Tampoco el Estado le va a la zaga, pues de los mejores ingresos de los súbditos y de la mayor circulación (no olvidemos la existencia de importantes impuestos que la tienen como base) se obtendrán fondos crecientes para el erario público.

Tan idílica situación, que la cruda realidad no supo o no quiso apoyar (recordemos los "tira y afloja" motivados por la suspensión de la tasa o los motines de 1766$)^{21}$, aparece cimentada en una teoría de corte libre-

\footnotetext{
${ }^{18}$ Respuesta fiscal del Sr. D. Pedro Rodriguez Campomanes del Consejo de S. Mgd. y su Fiscal en el Supremo de Castilla sobre el comercio de granos, 1764.

${ }^{19}$ Cfr. Manuel Bustos Rodriguez: El pensamiento socioeconómico de Campomanes, Oviedo, Inst. de Estudios Asturianos, 1982, pp. 166-172.

${ }^{20}$ Cfr. Respuesta fiscal (A.C., 24/21), pp. 42v-43.

${ }^{21}$ L. Rodriguez, op. cit., pp. 179-223.
} 
cambista, extensamente desarrollada y matizada por Campomanes en su Respuesta Fiscal de 1764. Allí declarará solemnemente que el precio de los géneros depende del "consentimiento universal de la Nación en sus contratos", y que la tasa de granos hasta entonces vigente "envilece el precio» ${ }^{22}$, beneficiando tan sólo algún que otro particular aislado o comunidad de granjeros (que en el argot campomanista equivale a comunidad de religiosos con propiedades de tierras de las que viven holgadamente). Unicamente una concurrencia libre de trabas, a expensas de la "estimación universal» podrá lograr, mediante un equilibrio basado en mutuas compensaciones, ese beneficio general de toda o la mayor parte de la sociedad y la abundancia de grano; sólo una concurrencia tal puede conseguir, en definitiva, un precio justo natural, diferente del artificialmente impuesto desde fuera del propio mercado ${ }^{23}$. A cada tiempo dará lo que corresponde, el precio cabal: en época de cosecha escasa, aparte de traer grano de donde abunda, la subida de precios producida compensará al labrador del poco cereal logrado; por el contrario, en época de abundancia, el precio desciende, beneficiando al consumidor, pero puede el vendedor sacar grano fuera, a donde haga falta, compensando asi las posibles pérdidas.

Por eso la acción del Estado al respecto debe cambiar. Campomanes, con una actitud liberal precursora de Adam Smith, pedirá a la Administración que no suplante al comerciante. "Lo que en otros Payses (de nuevo el ejemplo inglés) es puro negocio de comercio, se hace en los Payses donde no está conocida la circulación de granos (España), materia de Estado, y costosa" ${ }^{24}$. Este dejar actuar exige, por lo tanto, que la Administración no discrimine, otorgando patentes de monopolio o estanco a compañias, puertos o simples particulares, y que deje de fijar los precios por medio de tasas. Las leyes de ella dimanadas se dirigirán al fomento de la agricultura, cortando los abusos que se le oponen y haciendo posible el libre comercio. Será, pues, el particular quien recoja los beneficios de esta cesión, ya que, a "la fama del precio", todos concurrirán a vender libremente, siendo las leyes económicas de la oferta y la demanda las que lo lleven a su justo término ${ }^{25}$.

Esta liberalización se extiende también a otros ámbitos de no menor relieve: el de la libre disposición de la tierra, que vimos anunciada en

\footnotetext{
${ }^{22}$ Respuesta fiscal, pp. 19 y 20.

23 Ibidem., p. 30 v.

24 lbidem, pp. 25 y 42.

${ }^{25}$ Jbidem, pp. $25,19-20$ y 24 respectivamente.
} 
1752. Recordemos que allí se nos proponía la necesidad de una legislación que facilitara el aumento de los rendimientos a través de arrendamientos bajos a largo plazo, y la posibilidad de redención de los mismos, de cara a obtener alguna vez la plena propiedad de la tierra. Ahora, Campomanes señalará el valor que la seguridad y el sentido de pertenencia reportan a la mejora agrícola, al generar en el labrador un mayor interés por lo que la tierra produzca. Asegurando al colono que pague sus rentas el mantenimiento de sus campos, se logrará que "cobre cariño a la tierra, la plante, la cerque y la mire como un patrimonio, o manantial continuo de riquezas inagotables" ${ }^{26}$. Estamos en una economía del interés como motor de la inversión y la reforma que Campomanes vincula al desarrollo agrario. Sólo cuando el campesino, sea éste propietario o arrendatario, comprende que el fruto de sus desvelos revierten en beneficio propio y de su familia, se preocupa verdaderamente de la mejora permanente de sus trabajos con vistas a sacarles mayores rendimientos. Por otro lado, Campomanes no advierte en principio contradicción entre propietario y arrendatario, siempre que a este último se le den seguridades: el primero se beneficia con el alto precio de los productos que vende en el mercado libre, en tanto que el segundo participa también de los mismos beneficios, sin un incremento del canon pagado en concepto de arrendamiento que reste importancia a los mismos. Pero consciente de la realidad, el asturiano constatará que el labrador más necesitado se ve obligado a vender aunque no quiera, mientras «el cosechero rico, el dueño de terrazgos y el arrendador de diezmos" pueden regular sus ventas, guardando para vender en el tiempo que más cueste el producto. De esta forma se introduce un elemento de duda nada desdeñable en la coherencia del sistema. En todo caso, el Estado ve también aquí disminuida su función, a pesar de que, finalmente, salga beneficiado; con to cual se refuerza el papel del individuo y del libre mercado.

Todo este planteamiento se redondea en el Tratado de la Regalía de Amortización de 1765, donde Campomanes subraya la importancia de los bienes raíces (tierras preferentemente) en manos de los seglares y el perjuicio que producen las propiedades amortizadas por la Iglesia, en cuanto obstáculo al libre acceso a la propiedad por parte de los laicos y al aumento de su productividad. No vamos a detenernos en el tema de las "manos muertas", conocido sobradamente por varios estudios a él consagrados; por el contrario, preferimos centrarnos en la relación exis-

${ }^{26}$ Ibidem, p. 32. 
tente entre posesión de la tierra y aumento de los beneficios, tan querida del asturiano.

En efecto, a partir de la declaración de que los bienes raíces o estables "son el patrimonio privado de las familias seculares, que deben cultivarles; sacar de la cosecha su sustento; y darlas circulación ya en el comercio, ya en las producciones artificiales de las artes, o en el consumo de los habitantes" ${ }^{27}$, Campomanes reabunda en su idea de la posesión y libre disposición de la tierra como base de la mejora social del campesino y aumento de la productividad de sus cultivos. Se desarrolla asi una faceta del tema agrario más social que la anterior en el tiempo, vinculada mayormente por el asturiano a los conocimientos y la mecanización. No hay inversión alguna, ni preocupación por un estudio mayor del campo - parece decirnos Campomanes ahora - sin arraigo en la propiedad ni perspectivas de mejora económica. Esta preocupación del reformista y hombre de Estado se despliega a través de la íntima relación entre los hechos, dentro del plano económico-social, llegándose a una separación arriesgada entre el orden político y el moral. Pero, vayamos por partes.

Campomanes percibe que la felicidad del Estado (que él identifica -no lo olvidemos - con la de la sociedad) estriba en la riqueza repartida. Al contrario, la desigualdad es fuente de proletarización -lo opuesto del campesino activo y libre deseado- y mendicidad, que desanima al matrimonio, haciendo disminuir la población y debilitando al Estado ${ }^{28}$. Mas, desde el punto de vista político conviene introducir un atenuante: a la Monarquía y a la propia sociedad interesa la existencia de ciertas fortunas de consideración. Con ellas, además de sostenerse la nobleza, pilar fundamental del Estado monárquico, cuya dignidad exige unos recursos económicos acordes con su rango, se beneficia el conjunto, gracias al flujo de riqueza que se genera. Al orden moral importa, sin duda, la legitimidad o ilegitimidad de las riquezas acumuladas, pero los juicios resultantes de la reflexión corresponden al "fuero interior»; por el contrario, al orden político interesa únicamente que «los hombres sean indus-

27 Discurso sobre el fomento de la industria popular, Madrid, Imprenta de D. Antonio de Sancha, 1774 , p. 3. Existe reimpresión del Ministerio de Hacienda, Instituto de Estudios Fiscales, con Estudio Preliminar a cargo de John Reeder, Madrid 1975. Nuestras citas pie de página siguen la paginación de esta última obra.

${ }_{28}$ Tratado de la Regalia de Amortización. Madrid, Imprenta Real de la Gaceta, 1765 (Reimpresión facsímil con estudio preliminar de Frco. Tomás y Valiente, Madrid, Edcs. de la Revista del Trabajo, 1975), pp. 280-81. 
triosos y activos en acumular bienes", puesto que, de esta riqueza se derivará un mayor consumo y, vinculado a él, el desarrollo industrial. La nobleza es la clase (sic) socialmente mejor situada para asumir este papel, por interés propio (la dignidad de su rango exige cierta riqueza) y del Estado (una nobleza económicamente solvente es fundamento de la Monarquía) ${ }^{29}$. El asturiano resumirá en dos las cualidades definitorias de la aristocracia: permanente y rica. Conviene entonces dejar que los vínculos puedan ser mejorados: pero también en este punto hay sus matices.

Conviene que haya ricos, pero no de cualquier tipo. Campomanes distingue dos grupos: eclesiásticos y seglares. Es a los segundos a quienes se dirige su llamada; en cambio, a los primeros pertenece la austeridad y el desprendimiento de bienes. El crecimiento de los unos va unido para él al empobrecimiento de los otros ${ }^{30}$. ¿Quién deberá ceder? Sin duda, los religiosos (sobre todo regulares) llamados a colaborar en el bien espiritual, pero también material, de los seculares, y, por su ministerio, a vivir en continencia y moderación ${ }^{31}$. Aquí precisamente se inscribe la cruzada campomanista contra los bienes de «manos muertas» ya aludidos. A diferencia de los vínculos nobiliarios, los correspondientes al estado eclesiástico deben ser cortos (sic), para evitar así las consecuencias no deseadas ( = las opuestas a las que derivan del enriquecimiento nobiliar): despoblación y aumento del número de tierras yermas; disminución de los habitantes y del consumo; contracción económica consiguiente; ... ${ }^{32}$.

Campomanes señala que no todas las riquezas acumuladas lo fueron por "malos medios"; pero ello no evita del todo la posibilidad de un choque entre los dos planos (moral y político), cuando los bienes no provienen de actividades lícitas. Sin embargo, el Gobierno, por encima de valoraciones éticas, interesan únicamente los efectos y la utilidad que del hecho acumulativo se deriven. No es aquí lugar para el desarrollo del alcance de esta distinción sutil y a la vez trascendente, que el político

29 Ibidem, pp. 280-81.

30 Se comprenden asi los dictámenes de Campomanes contra los monjes granjeros de 1764 y 1768 (Antonio DomíngUEz ORTIZ: “Campomanes y los 'monjes granjeros'. Un aspecto de la politica eclesiástica de la llustración", Cuadernos de Investigación Histórica, n. 1 , 1977, pp. 99-109).

31 La opulencia (sic) es necesaria al seglar y funesta al eclesiástico, expresa Campomanes (Tratado de la Regalía, p. 54).

32 Ibidem, pp. 280-81. 
Campomanes establece, aunque sí conviene al menos ponerla de manifiesto a fin de centrar mejor el espacio donde se instala la teoria agraria campomanista por los años sesenta, en su compromiso con una labranza libre de trabas, capitalizada (retoma indirectamente su idea de 1752) a través del flujo monetario, y con el campesino - proletario o arrendatario- como protagonista principal. Una teoría, en definitiva, relacionada con los componentes puramente técnicos, que no olvida (antes bien potencia) los económicos generales, los sociales y hasta los éticos.

La idea de una economía cuyos ramos están estrechamente conectados entre sí adquiere ahora también carta de naturaleza. En su escrito dirigido a Craywinkel, Campomanes establece que el florecimiento de la agricultura tiene que ver con el progreso de las fábricas y la absorción por ellas de mano de obra. El argumento es simple: el desarrollo industrial (sea como fábricas de géneros finos, sea de bastos), al permitir mayores perspectivas de trabajo y mantenimiento a los particulares, anima los matrimonios y aumenta el número de habitantes. Con él crece la demanda de primeras materias, que impulsa el incremento de los precios, proporcionando a quienes viven del campo la ya referida mejora de sus beneficios, compensatoria de la pérdida de exportaciones. El círculo se cierra al revestir esta capacidad adquisitiva mayor de propietarios y arrendatarios de la tierra en un crecimiento del consumo de bienes manufacturados, beneficioso para los artesanos que trabajan en las fábricas. Además, la industria, por sí misma, constituye un importantísimo apoyo para los labradores, en lo que, durante la tercera etapa (años setenta), Campomanes denominará la «industria popular», idea aún poco desarrollada por las fechas que nos ocupan.

En lo que respecta al comercio, el asturiano también relaciona su desarrollo con ventajas para el agricultor. Tomando el ejemplo inglés como punto de referencia, Campomanes encuentra, junto al incremento del consumo y la población, el despliegue de la marina y el comercio que facilitan la salida de los frutos del campo contribuyendo de esta forma a la estabilidad del labrador.

Para dar impulso a la política económica propuesta a lo largo de estos años sesenta, no basta sólo con la acción del Gobierno. No debe, pues, extrañarnos que Campomanes eche ahora mano, siguiendo modelos europeos, de las Sociedades de Agricultura, por cuya constitución aboga ya en 1763. Efectivamente, en este año, escribe un Discurso sobre los verdaderos principios de fomentar el cultivo de las tierras en España, donde propone las reglas más convenientes para sacar el má- 
ximo provecho de la referida institución ${ }^{33}$. Su contenido aparece explicitado luego en el tratado sobre libre comercio $(1764)^{34}$. Se pretende convocar a personas diversas, unidas por el celo del bien público y el amor a la patria. Tales patriotas, en línea con la sensibilidad de las $L u$ ces, habrían además de ser verdaderos filántropos, entregados a su labor sin esperar por ella remuneración ni recompensa. A través de ellos, el Gobierno podría contar con unos inestimables auxiliares en provincias, dispuestos a vigilar en ellas el cumplimiento de las leyes promulgadas. Así, la operatividad de las medidas reformadoras en el ámbito agricola quedaba asegurada y vencido uno de los obstáculos más importantes a las mismas. $Y$ no quedaban en esto agotadas sus posibilidades, puesto que el objetivo final de las Sociedades radicaba en promover la agricultura y el libre comercio de granos. La necesaria sintonía con el Gobierno se lograría, no sólo compartiendo unos mismos fines, sino también mediante unas comunicaciones periódicas y fluidas con su Consejo, protagonista central de las reformas según más arriba señalábamos.

Sobre estas Sociedades o Academias de Agricultura, antecedentes más inmediatos de los Amigos del País que Campomanes promoviera abiertamente a partir de su Discurso sobre el fomento de la industria popular de 1774, el asturiano escribirá una carta al Marqués de Grimaldi el 12 de enero de $1763^{35}$. En ella le expresa la necesidad de crear una Academia de Agricultura (sic) en la Corte, que reconociera, reimprimiera y extractase las obras españolas de agricultura, propagando al mismo tiempo su estudio a través de las provinciales. Como estímulo se otorgarian seis premios anuales sobre problemas concernientes a los ramos de la labranza y los medios de estimularla. Entre los académicos seleccionados se incluyen dos matemáticos «inteligentes en la maquinaria para la dirección de los nuevos instrumentos de agricultura», dos físicos hábiles para la historia natural, y un secretario capaz y hombre de letras; todos ellos sin sueldo. La comunidad de intereses entre estas instituciones y el Gobierno se asegura haciendo recaer la Presidencia de la fundada en Madrid en el Primer Secretario de Estado.

Dos días después contestaba el ministro Grimaldi a Campomanes mostrándole su contento por la idea. Por último, el 24 de enero del

\footnotetext{
${ }^{33}$ A.C., $14 / 2$.

${ }^{34}$ pp. 53 v. -54

35 A.C., 22/25,3.
} 
mismo año le expresará abiertamente su parecer favorable al proyecto, que poco más tarde sería una realidad ${ }^{36}$.

\section{EL PERIODO DE MADUREZ}

Por medio de las Sociedades de Agricultura o del establecimiento de las nuevas poblaciones de Sierra Morena (Fuero de 1767), el asturiano conseguiría llevar a la práctica algunas de sus ideas pertenecientes al ámbito agrario. En la década del setenta, aproximadamente, entrarán éstas en una nueva fase con la redacción de una trilogía de Discursos, obras cumbre del pensamiento campomanista, entre 1773 y 1775; de ellas, la dedicada a la Educación de los labradores españoles será estrella en el tema que nos ocupa ${ }^{37}$. La legislación agraria de Carlos III sigue ahora básicamente las propuestas de nuestro prócer, aunque no siempre se apliquen como hubiera sido su deseo.

Desde la Fiscalía del Consejo de Castilla, el asturiano intensificará su acción reformista interviniendo en diversos frentes, polémicos en su mayor parte. Relacionados con la labranza hay dos especialmente importantes: el Expediente de reforma agraria y la Mesta. El primero se abriria por los años sesenta con el escrito elevado a petición de los diputados extremeños contra el Honrado Concejo de la Mesta, adquiriendo impulso en la siguiente década (1771) con el famoso Memorial Ajustado de Vicente Paino, tras el que intervendrá Campomanes. El remate final de este largo proceso, en el que se imbrica también el Expediente de reforma agraria, culminaría con el proyecto de Jovellanos ante la Sociedad

${ }^{36}$ Contento en Carta del Marqués de Grimaldi a Campomanes, El Pardo, 15-1-1764 (A.C., 22/25, 2. Epist., p. 98). Parecer en Carta del M. de Grimaldi a Campomanes, El Pardo, 24-1-1764 (A.C., 22/25, 1. Epist., p. 99). El 20 de noviembre de 1765 la Academia de Agricultura de Galicia nombrará a Campomanes Académico Honorario de la misma, en muestra del alto concepto en que tiene V.S. cuyo favor y luces se promete las mejores ventajas y adelantamientos (A.C., 11/38. Epist., p. 135).

${ }_{37}$ Discurso cit. ut supra p. de p. 27; Discurso sobre la educación popular de los artesanos, Madrid, Imprenta de D. Antonio de Sancha, 1775 (Reedic. cit. ut supra p. de p. 27); Discurso sobre la educación de los labradores españoles, en A.C., 24/7. Sobre el valor de este último vid. M. Bustos Rodriguez: "Una obra fundamental de Campomanes: El "Discurso sobre la educación de los labradores españoles", Comunicación al Coloquio Internacional Carlos III y su siglo, Madrid, noviembre, 1988. 
Económica Matritense el año de 1794. Entre medias se enmarca la comisión recibida del rey por el asturiano para presidir el Consejo de la Mesta, en principio hasta 1780 , luego prolongado dos años más, hasta 1782. Es una época de beligerancia con la vieja pero poderosa institución ganadera, que alcanza su cénit con el Memorial Ajustado del Expediente de Concordia que trata el Consejo de la Mesta con la Diputación General del Reino y Provincia de Extremadura de 1783, y en las medidas tomadas por Carlos III en desfavor del primero entre $1780-90^{38}$.

Campomanes vuelve ahora al tema del conocimiento y la enseñanza como clave de la reforma del campo. Insistiendo en sus preocupaciones de 1752, el asturiano señalará la importancia de un cambio de dirección y de objeto a este respecto ${ }^{39}$. En este sentido, la ciencia que adquieran los labradores debe ser muy distinta de la que él mismo da en llamar abstracta y sublime, por lo general vinculada a la metafísica ${ }^{40}$. Si antes era ésta quien predominaba, ahora convienen los cimientos sólidos, instruidos y útiles que contribuyen mejor a la felicidad de los súbditos, meta a que se dirige la acción del Estado. Bajo de tales premisas, la educación de los labradores debiera abarcar cuatro ámbitos bien delimitados, que hasta el presente no se habia ocupado de precisar: el natural, civil, cristiano y científico. El primero, dimanante del corden que el Criador prescribió a los vivientes para su conservación", equivale al instinto en los animales; por el segundo se pone coto a los desarreglos sociales; el tercero alude a la religión, el "vínculo más fuerte de los hombres", y "corrige y modera" casos en los que no bastan las costumbres ni las leyes humanas; por último, la científica, relativa al trabajo de los campesinos, destinada a que éstos obtengan lo suficiente para mantener a su familia ${ }^{41}$. Interesa recalar en esta cuarta, a fin de conocer los contenidos teóricos y técnicos que Campomanes señala a los labradores con vistas a la mejora de sus tierras y de sus propias condiciones de existencia.

Se propone un conocimiento de medios y aprovechamientos. Para ello es preciso saber las posibilidades que ofrecen los cultivos, en especial los nuevos. Los medios de explotación de la tierra, relacionados con lo anterior, ocupan también un lugar importante, puesto que permiten

38 El Memorial fue publicado en Madrid en 1783 en dos vols.

${ }^{39}$ Discurso sobre el fomento, p. IV.

40 Ibidem, pp. I-II.

41 Discurso labradores españoles, pp. 7-8, 11, 14-15. La numeración es nuestra Cfr. mi comunicación cit. ut supra nota 37. 
obtener un uso de las plantas, frutos y animales más adecuado. Los adelantos en el medio agrario constituyen, asimismo, una fuente esencial de información. $Y$, en un plano puramente teórico, el conocimiento de los tres Reinos de la Naturaleza (vegetal, animal y mineral), en particular de la Historia Natural ocupa un lugar relevante ${ }^{42}$. La gimnasia y los ejercicios físicos completarian la educación del labrador.

Campomanes pide la adaptación de la enseñanza al lugar donde ésta vaya a ser impartida, y para ello apelará al Gobierno, a las Sociedades Económicas de Amigos del País - que han sustituido ya prácticamente a las Sociedades y Academias de Agricultura-, a los párrocos y propietarios de tierras, a fin de que se erijan en verdaderos maestros de los campesinos, ejerciendo su labor en la confianza de que el ejemplo, al igual que las posibilidades de ganancia, servirán de estímulo a esos para su aplicación ${ }^{43}$.

En los Discursos que Campomanes dedica por los años setenta a artesanos y labradores se perciben las mismas relaciones - analizadas en el período anterior- entre los diferentes ramos de la economia, la población y las posibilidades de empleo. Dado que la segunda, a quien el asturiano concede una importancia excepcional, depende básicamente de las terceras, convendrá el fomento de dichos ramos al objeto de que la meta poblacionista que se persigue pueda ser alcanzada. (La población numerosa, además de aumentar los efectos impositivos del Reino, desarrolla el consumo, del que dependen las ganancias de campesinos $y$ artesanos) ${ }^{44}$. Pues bien, tomando como referencia el arbitrista Fernández Navarrete, ninguna actividad económica resulta tan importante para nuestro personaje como la agricultura, a la hora de conseguir el referido incremento demográfico, que pasa, según hemos visto, por el arraigo y las posibilidades de trabajo de las familias. De ahí las afirmaciones vertidas por Campomanes en su Discurso sobre la educación de los labradores: La agricultura es el "nervio del Estado"; en ella "cifra el Soberano su verdadero poder" y la nación su mayor riqueza "que es el gran número de habitantes" ${ }^{45}$.

\footnotetext{
${ }^{42}$ Discurso educación popular, p. 8.

${ }^{43}$ Discurso labradores, pp. 35-36, 59 y 23 respectivamente.

44 Ibidem, pp. 13 y 15.

45 Ibidem, p. 38.
} 
En un país de mayoría campesina, el asturiano entiende que la agricultura es la ocupación más necesaria al hombre, así como la más natural y sencilla; y que, por ello, resulta también el empleo más natural y preciso ${ }^{46}$. La industria, con la que también relaciona población y trabajo, ocupa en cambio un puesto secundario. Su interés estriba mayormente en el carácter de auxiliar de la agricultura que puede poseer (proporcionar unos beneficios suplementarios al campesino, al tiempo que los autoabastece de algunas manufacturas), sobre todo en lo que ahora se denomina la industria popular. Campomanes lo expresa sin ambages: «Aunque son necesarios los oficios (artesanado), es más provechosa la agricultura» ${ }^{47}$. Carácter complementario que también atribuirá a la ganadería.

Tal punto de vista se trasluce en la comparación entre las cuatro figuras claves del proceso productivo (agricultor, ganadero, artesano y comerciante). El labrador, hombre robusto y prolífico, vive sometido a vejaciones. Es, por lo general, pobre e ignora lo que pasa. Cansado de las penosas fatigas del campo, anhela el descanso. En cuanto a su forma de ser, "es hombre de bien y buen cristiano, criándose en las aldeas sin aquel tropel de malos exemplos, mormuraciones, embidias y ociosidad que arruínan las costumbres en las ciudades y villas populares, de donde se comunica el contagio al resto de la nación" ${ }^{48}$. Así pues, virtud en el campo y vicio en la urbe.

Frente a un labrador que trabaja de sol a sol en su heredad y soporta las inclemencias del tiempo, "el artesano se mantiene en su taller, abrigado de todas las estaciones, y vive ocupado en faenas más descansadas". En cambio, los campesinos "no pueden, sin el auxilio de la industria, sostenerse, debiendo esperar las cosechas, y adelantar todos los gastos de la labranza, sementera y recolección; además de correr el riesgo de la carestía o esterilidad". Por el contrario, "el artesano puede recibir diaria o semanalmente el producto de su trabajo; y aunque tenga un número considerable de hijos, todos hallan facilidad de establecerlos, enseñándoles bien su oficio". La pobreza del agricultor es tal que "apenas podrá colocar más de un solo hijo en la labranza, y no encuentra tierra, ganado, aperos y granos con que destinar a los demás hijos" ${ }^{49}$.

\footnotetext{
46 Ibidem, pp. 13 y 12 respectivamente.

47 Discurso educación popular, p. 357.

48 Discurso labradores, pp. 13, 29-30 y 53.

49 Discurso educación popular, pp. 275 y 54-57 respectivamente.
} 
Ambos oficios, aunque primado el uno sobre el otro, son necesarios y se complementan. Igual sucede con el de ganadero, que Campomanes no desea en estado puro, sino asociado al de labrador. El primero sólo acumula en la persona que lo ejerce elementos negativos: «es hombre rico (en el sentido peyorativo del término), ocioso, y sabido, que codicia toda la superficie del terreno español para vender su lana a los países extraños" ${ }^{50}$. Se evidencia en estas palabras la experiencia adquirida por el asturiano en el tema del Memorial Ajustado y como Presidente del Concejo de la Mesta. La institución, al representar al ganadero puro y transhumante, se ha convertido para él en la bête noire de las reformas agrarias propugnadas, $y$, por consiguiente, lo que en la década anterior no fuera sino una tenue presentación de los perjuicios provocados por la Mesta y de su virtual oposición al desarrollo del campo, se convertirá ahora en crítica abierta a este enemigo fundamental del mismo ${ }^{51}$. Pero sigamos comparando los oficios.

Al igual que el artesano y el ganadero, también el comerciante ocupa un lugar, en parte secundario, aunque complementario también, con respecto a la profesión de labrador. En su escrito sobre el libre comercio de granos, Campomanes expuso ya la significación del comerciante, dedicado a posibilitar con su ejercicio la salida de los frutos de la tierra, base de los beneficios obtenidos por propietarios y arrendatarios, facilitando al mismo tiempo el consumo al llevar el producto hasta aquellos centros donde se necesita. No podemos entrar en el desarrollo de este interesante tema, que ahora retomará Campomanes, pero que desborda el objetivo de nuestro estudio.

Defendiendo, pues, el interés social de la agricultura, a la par que la promoción del campesino, el asturiano nos introduce de lleno en el corazón de su política económica, básicamente dirigida a extender la superficie cultivada y dotar al labrador de autonomía para actuar sobre las tierras: líneas de acción ambas que cimentan la llamada reforma agraria, la cual terminará chocando a la postre con los intereses de la Mesta y de las comunidades de eclesiásticos "granjeros", a quienes Campomanes fustigará sin tregua desde sus escritos y el Consejo de Castilla.

El impulso a las roturaciones, animado por el crecimiento de los precios agrícolas por estos años, exige la liberalización que el asturiano

${ }^{50}$ Discurso labradores, p. 29.

${ }^{51} \mathrm{Cfr}$. M. Bustos Rodriguez: "Campomanes y la Mesta. La nueva coyuntura del siglo XVIII", Hispania, XL (1980), pp. 129-151. 
planteara en el período anterior, todavía en el papel. Ahora, sin embargo, nuestro prócer parece ir más lejos. Los rompimientos de tierras deben, en su opinión, discurrir al ritmo exigido por el crecimiento poblacional. Para ello será preciso ganar espacio a las superficies de pasto y echar mano de las dehesas, oponiéndose a los intereses de la Mesta. Como para tranquilizar los ánimos, Campomanes intenta mostrar, mediante recorrido por la historia del Concejo, que tan sólo se trata de una medida de mera justicia ante los injustos privilegios acumulados por la institución ganadera y la connivencia de que ha gozado por parte de las autoridades desde muchos años atrás ${ }^{52}$. No se trata, pues, de suprimirla, sino de poner coto a sus desmanes. Las ovejas transhumantes pastarian en los terrenos sobrantes a los agricultores, y el espacio perdido quedaría compensado por la introducción de pastos artificiales a cargo de estos últimos. Pero tal innovación, en realidad, suponia un grave perjuicio para los propietarios de ganados mesteños. $Y$ es que Campomanes posee un ideal distinto: el agricultor que a la vez es ganadero y alterna sin oposición en sus tierras pastos con tierras de labor, dando, eso sí, preponderancia a las segundas con respecto a los primeros. Se trata, como expresamos antes, de dar autonomía al labrador, dotándole para ello de los medios necesarios para desarrollarla.

No se queda en esto sólo el asturiano. Si en su Discurso sobre los verdaderos principios de fomentar el cultivo de 1763, había manifestado la conveniencia de restaurar las antiguas leyes municipales que limitaban a cada vecino las tierras que podía labrar, a fin de evitar una concentración excesiva de la propiedad que obligase a sus paisanos a emigrar; ahora, por el contrario, se muestra más liberal, considerando los cercamientos como elemento clave de la reforma agraria, a costa incluso de los baldíos y tierras comunales, que pasan de esta manera a uso privado. De esta forma, permitiendo al particular disponer de la tierra, podrían lograrse dos objetivos fundamentales para remover radicalmente los obstáculos culpables del atraso de la agricultura española: mejorar los rendimientos y racionalizar el aprovechamiento de los campos ${ }^{53}$.

Para los arrendatarios carentes de propiedad, Campomanes dispone también una serie de medidas que enlazan con las de 1752: cánones bajos para arrendamientos de larga duración ${ }^{54}$. Por medio de ellos, dis-

${ }_{52}$ Discurso labradores, pp. 34, 31-32, 37, 43-45 respectivamente.

53 Ibidem, pp. 17, 22, 32 y 18-19.

54 lbidem, p. 33. 
pondrían de la tierra como si ella fuere realmente suya, arriesgándose a innovar e invertir buscando beneficios. En cuanto a las mejoras resultantes, correrían a cargo de los dueños. Incluso se contempla alguna posibilidad de acceso a la propiedad a medio o largo plazo, a través de la redención del arrendamiento propuesta en 1752, o por los repartimientos de suertes sobre las tierras baldías y comunales, las cuales constituyen el núcleo de la reforma agraria emprendida por la llustración española.

¿Cuál sería el papel del Estado en esta situación? Campomanes le concede un carácter subsidiario. Puesto que la iniciativa corresponde a los particulares, toca a la Administración el facilitarla mediante la acción legislativa. Las leyes, en resumidas cuentas, deben dar auxilio, remover prácticas viciadas (como las usuales de la Mesta), apoyar la experimentación, velar por la instrucción y salud de los campesinos ${ }^{55}, \ldots$

El interés de Campomanes por los temas agrarios remonta a su juventud y está alimentado por el empirismo agrícola que se pone de moda en Europa durante la primera mitad del siglo XVIII, destacando por su influencia el inglés, J. Thull y el francés Duhamel de Monceau. En esta primera etapa, el asturiano, libre aún de responsabilidades de Gobierno, se adentra en la necesidad de revolucionar la naturaleza, métodos y objeto del conocimiento, aplicando sus resultados al medio agricola hispano. Las propuestas concretas son todavia incipientes, si bien apuntan en una dirección de gran desarrollo posterior (rompimientos, introducción de nuevos cultivos, fijación del campesino, política de rentas).

En el marco de los años sesenta, con un Campomanes comprometido con las reformas ilustradas al calor del Gobierno de Carlos III, se delinea con nitidez lo que serán los ejes fundamentales de su política económica aplicada al campo. Es una época de escritos enjundiosos (Tratado de la Regalía, Respuesta Fiscal sobre el libre comercio), donde Campomanes desea enlazar con la tradición española de pensamiento económico (la divulgación de los arbitristas será, sin embargo, más tardia). Establece ahora un espacio amplio para el librecambismo, así como el cuadro de relaciones entre las distintas ramas de la economía, separando a la par, peligrosamente, el orden moral del político, a fin de fomentar el gasto que

\footnotetext{
${ }^{55}$ Ibidem, pp. 18, 21, 23 y $28-29$ respectivamente.
} 
desarrolla la producción y el empleo. Todo ello sin merma para las medidas concretas de reforma, que encontrarán en las Sociedades Agrícolas una de sus expresiones más claras.

En el culmen de su poder, el Campomanes de los años setenta es el de los Discursos más divulgados. Allí, sin olvidar sus preocupaciones de primera hora (revolución del conocimiento, por ejemplo), aboga ya decididamente por informar la legislación carolina, con vistas a remover los principales obstáculos que, a su entender, impiden la renovación del campo español. Cristalizan ahora sus propuestas liberalizadoras, que le llevan a un enfrentamiento tenaz con la Mesta, en pro de un campesino arraigado y con interés por mejorar el rendimiento de sus tierras. El Estado, en este contexto, deberá representar un papel meramente subsidiario. 